\title{
Planning for the Pediatric Patient During a Disaster
}

\author{
Jessica A. Zagory ${ }^{1}$ - Aaron R. Jensen ${ }^{1} \cdot$ Rita V. Burke ${ }^{1} \cdot$ Jeffrey S. Upperman $^{1}$
}

Published online: 13 October 2016

(C) Springer International Publishing AG 2016

\begin{abstract}
Purpose of Review Disaster and mass casualty events are unpredictable and quickly overwhelm response systems. Children are affected by disasters; however, pediatricspecific disaster preparedness is lacking. Preparedness is required at the individual, physician, and hospitals/community levels and constitutes material allocation, education, and communication. Specifically, pediatricians, pediatric subspecialists, and pediatric surgical subspecialists have important roles during a disaster, mass casualty, or pandemic response; thus, integration of both community and subspecialty physicians is important. Disaster response is not limited to planning and response; major efforts in recovery, reunification, community health safety, and follow-up are required.

Recent Findings Events have highlighted the need for improved preparation and execution of mass casualty response. There is a need for training in the event of a mass casualty disaster, and pediatric professionals have indicated that they do not feel adequately prepared to care for children during such events. Incorporation of pediatric-specific simulation scenarios can help address this deficiency.
\end{abstract}

This article is part of the Topical Collection on Pediatric Trauma

Jeffrey S. Upperman

jupperman@chla.usc.edu

Jessica A. Zagory

jzagory@chla.usc.edu

Aaron R. Jensen

ajensen@chla.usc.edu

Rita V. Burke

riburke@ chla.usc.edu

1 Department of Surgery, Children's Hospital Los Angeles, $4650 \mathrm{~W}$ Sunset Blvd MS 100, Los Angeles, CA 90027, USA
Summary Thus, efforts to incorporate pediatric-specific education, disaster simulation, and preparation including a multidisciplinary approach integrating families, physicians, and hospital and community organizations are required.

Keywords Pediatric trauma $\cdot$ Disaster planning $\cdot$ Mass casualty

\section{Introduction}

Disasters and mass casualty events are often unpredictable and can quickly overwhelm any emergency system. Recent events have highlighted the need for improved preparation and execution of mass casualty response [1-8]. Although trauma is the leading cause of morbidity and mortality in the pediatric population, and children make up $25 \%$ of the population in the USA, they are seldom taken to pediatric trauma centers (PTC) due to distance and the lack of integration of pediatric care into disaster planning [9-13]. Because care for the pediatric patient is often omitted from mass casualty planning, it is imperative that all healthcare professionals, from the first responders to the subspecialty physicians and hospital administration, be versed in preparing and caring for children before, during, and after a disaster $[1,14,15 \bullet \cdot]$.

Children are inherently different than adults, and recognizing these differences is critical during emergencies since the pediatric population is highly vulnerable, especially the younger age groups. These differences can be divided into behavioral/developmental and anatomical/physiological factors [16]. Due to age or developmental delay, children may not be able to speak, making it difficult to communicate their identity, caregiver, or their injuries. They rely on others for basic needs such as nutrition, shelter, and transportation; during an emergency, children may not know which way to go, 
sometimes even approaching areas of danger due to curiosity, or not recognizing contamination by hazardous substances. Youth and immaturity can increase the child's risk of exposure, since substances can be absorbed quickly due to physiologic differences: children have an increased respiratory rate, heart rate, and metabolism; a relatively large body surface area; very permeable skin and membrane barriers; and are closer to the ground, where noxious substances may settle. Increased exposure to toxins during a developmentally critical period can have profound behavioral, neurologic, and physical consequences, including increasing the lifetime risk of malignancy due to carcinogen and radiation exposure, and long-term behavioral effects of trauma manifested in developmental regression, attention and behavioral disorders, enuresis, or somatic complaints [15••].

Once children are transported to receiving facilities, personnel, medications, and equipment must be available for specific pediatric needs. Recent studies have highlighted the need for adequate training in the event of a mass casualty disaster, and pediatric professionals have indicated that they do not feel adequately prepared to care for children during such events $[14,17]$. Incorporation of pediatric-specific simulation scenarios has helped address this deficiency [1, 18-24].

In this review, we highlight recent literature pertaining to preparation for families, healthcare professionals, and health systems; elements of disaster response during the event; and long-term needs of children after a disaster.

\section{Preparation}

Families and Community Disaster preparation begins in the home. Planning requires self-assessment, communication and information management, and contingency planning. Primary care physicians including pediatricians are key resources in helping families with children prepare and respond to threats. For instance, the 2009 H1N1 influenza pandemic demonstrated that families rely heavily on pediatricians for trustworthy and relevant information [15••]. However, despite disaster preparedness public education efforts, it appears that the majority of American families are not aware and ill-prepared to care for themselves for the recommended 3 days of self-sufficiency, recommended by the Federal Emergency Management Agency [25].

Children with special needs are especially vulnerable during disasters and mass casualty events. Special needs children may be technologically dependent or require specialized medications or support. Children with special health care needs often require services and support beyond those of the general population [26]. For instance, children with physical and emotional disabilities or other medical conditions may require medications such as insulin for diabetes, intestinal rehabilitation for short gut syndrome, or home oxygen for respiratory conditions.
In a recent survey study of rural families with children with special health care needs, only $64-77 \%$ of families were prepared for a disaster [25]. Less than half of the families surveyed had discussed or practiced disaster preparedness, and half had an emergency plan. Families with high social support, self-efficacy, and family resilience sources were more likely to have supplies and have overall preparedness. While a third of the families anticipated a disaster happening in the next 5 years, this did not correlate with increased preparedness. However, preparedness was increased among families that had a child with physical disability. The aforementioned physical disability finding was similar to other studies which found that physical disabilities are more easily planned for, while emotional and mental disabilities are associated with poor preparation for emergencies [27, 28]. Families with children followed in an intestinal rehabilitation clinic are also ill-prepared in the event of a disaster. A survey of families at a tertiary children's hospital with children requiring parenteral nutrition revealed that none of the families had an emergency communication plan, and few had an emergency supply kit [29]. Children requiring parenteral nutrition are incredibly vulnerable during emergencies because they require electricity sources for infusion pumps and refrigeration of their nutrition and need extra supplies for central line dressings or gastrostomy tubing. This mixed-methods pilot study highlighted the lack of preparation among intestinal rehabilitation families, and future work is needed to understand the factors driving the lapses in preparation in this and other populations [30, 31]. One remedy may be for physicians and community organizations caring for children with special health care needs to offer explicit guidance on emergency preparation.

Physicians Health care professionals are not only the source for disaster preparation information for families. Families should have their own plans in the event of a mass casualty disaster. Physician preparation should include skills and knowledge integral to minor trauma care of children, as well as other personal preparations such as written contact lists and care plans. In a recent study of pediatric healthcare employees at a tertiary pediatric hospital, almost half the employees expressed willingness to respond in the event of a disaster [32]. Those without dependents, men, and single individuals were more willing to respond, as well as those who had a shorter commuting distance. They found no association between previous disaster experience, disaster training, or personal preparedness and willingness to respond. Hospital systems can alleviate some of these barriers to response by providing compensation and childcare to employees, clearly outlining responsibilities in hiring contracts, and integrating personal preparedness plans with the institutional disaster plan [33•].

Physicians may have different roles during a disaster, depending on their training and experience. Pediatric surgeons, who are versed in pediatric trauma and pediatric emergency medicine, will be called on to participate in committees for 
hospital preparedness and may be asked to make critical decisions during a disaster event. While subspecialists may play important roles in critical care management, community pediatricians may assist with triage and oversee care for those who are not critically injured. No matter what the current practice entails, physicians who care for children will have an important presence during mass casualty events.

The role of the community physician is often overlooked in emergency preparedness simulations. Primary care physicians and community pediatricians deliver the majority of pediatric medical care and will be the ones families seek for information on emergency preparedness [15••]. Furthermore, they will provide valuable triage and treatment for children who do not require or cannot be transported to the nearest pediatric trauma center $[15 \bullet \cdot]$. They are a valuable community resource that can care for children with minor acute injuries, such as splinting fractures or suturing lacerations, distributing medications and medical countermeasures in the event of bioterrorism or mass contamination, and provide fluid and nutritional resuscitation. After a disaster, community physicians will be providing follow-up care for children involved in disasters. Follow-up care will include physical, mental, emotional, and social aspects, discussed below. Therefore, pediatricians must be included in disaster response training as they are integral members of the medical field with expertise in pediatric medicine, public health, and as representatives of the greater community.

Hospitals and Systems Many hospitals use mass casualty simulations to evaluate emergency preparedness efforts. Despite the application of different training and education programs, readiness appears to be lacking. Tegtmeyer et al. describe two approaches to education for a pediatric emergency mass critical care event: advance training and just-in-time training [34•]. Advance training includes seminars, grand rounds, and simulation events, and these events afforded the advantages of time, wide range of topics, and the ability to reach a wide audience. Just-in-time training is not as comprehensive but provides concise, targeted information relevant to the task at hand. Each have their advantages and disadvantages and, when employed together, can synergistically improve hospital personnel preparedness. Even among tertiary care pediatricians, only $35 \%$ of surveyed responders in a recent international study had disaster training, whereas $53 \%$ felt it should be an obligatory part of their curriculum [14]. Pediatric-specific training should be incorporated in all disaster plans, as even adult centers will receive pediatric patients during a mass casualty.

Mortelmans et al. conducted an international survey of pediatricians and pediatric emergency medicine physicians at tertiary care centers on the adequacy of hospital disaster planning. They found that whereas $95 \%$ of responders anticipated receiving pediatric patients after a mass casualty event, only $44 \%$ of these hospitals had specific emphasis on the pediatric patient as part of their disaster plan [14]. Approximately $50 \%$ of the hospitals had the ability to mobilize pediatric personnel, open pediatric intensive care beds, acquire specific pediatric intensive care supplies, accommodate for isolation, and have access to pediatric subspecialty physicians. In regards to post-disaster arrangements, only half of the hospitals had a plan for family reunification or posttraumatic psychiatric assessment. This was reflected in the 2013 Pediatric Readiness Assessment: less than half of US hospitals had a disaster policy in place that included the care of the pediatric trauma patient $[15 \cdot \bullet]$.

Recognizing need for engagement and education, a CHEST Consensus Statement was published pertaining to the care of critically ill patients during pandemics and disasters [33•]. Although not specifically targeted toward pediatric disaster preparedness, the consensus provides 23 suggestions regarding situational awareness, roles and responsibilities, education, and community engagement. Specifically, they target the integration of critical care physicians into planning and response and conclude that there must be a shift in operating systems - during a disaster, physicians and hospital systems will require departure from their regular operations as independent hospitals, to becoming a site in a network of responders to a disaster. The article highlights the need for robust information systems that will allow for coordination among health care professionals, hospitals, and government organization.

In 2005, a commuter train crash resulted in a mass casualty situation in Los Angeles and, after the event, the County implemented of a trauma system performance improvement program. After another crash in 2008, Cryer et al. analyzed the distribution of patients to trauma centers versus community hospitals [3]. They found that the majority of patients in the 2005 crash were transported to community hospitals, and this shifted to $93 \%$ of patients transported to trauma centers in 2008 after a trauma system performance improvement program. The change in trauma center destinations marked an improvement resource management by triaging critically injured patients to appropriate designated trauma centers, thus avoiding overwhelming the community, non-trauma hospital with trauma victims. This study highlighted the importance of a large trauma system with a robust communication system. The Los Angeles County disaster network underwent further simulation testing with an earthquake drill in 2008 [35]. The drill was an opportunity for hospitals to combine their independent disaster response plans into a community-wide effort. Few disaster resource centers, which are designated medical institutions as the central response for a catchment area, had a plan for pediatric disaster patients, from triage to follow-up resources. Additionally, institutions were often compartmentalized and had little communication and coordination with other centers or community entities. During an actual disaster event, the surrounding hospitals and community institutions will become vital in the care of the pediatric patient, and communication between the pediatric trauma center and its regional network will allow for patient and resource transfer. It is not only enough 
to have a hospital disaster preparedness plan; regional emergency preparedness leaders must prepare to work together.

\section{Disaster Response and Follow-Up}

Despite the best planning efforts, disaster events result in chaos, and casualties can quickly overwhelm a system. Pediatric trauma centers are equipped to care for children during a disaster, but they are not ubiquitous $[12,13,36]$. Previous investigators compared outcomes between pediatric and adult trauma centers. Pediatric trauma patients brought to an adult trauma center had acceptable outcomes compared to non-trauma centers, but children who suffered significant blunt trauma were found to have better outcomes if they were treated at a pediatric trauma center. Overall, children treated at a pediatric trauma center may have improved survival and functional outcomes [36-41]. These findings suggest that the disparity in pediatric trauma care during routine events may extend to outcomes after mass casualty events. Ongoing efforts should address improving pediatric care at adult trauma centers to minimize this gap.

The role of a pediatric trauma center during a mass casualty event depends on the location and scale of the event. If the event occurs in proximity of a pediatric trauma center, the medical and emergency management leadership should take a lead triage and treatment efforts. Patient movement includes reverse-triage, moving non-acute patients to outlying community hospitals in order to increase pediatric bed capacity [12, $13,42]$. If the disaster occurs outside the pediatric trauma center catchment area, hospital leadership may be consulted for coordination, transportation, or other accommodations for the pediatric surge. With the advent of wireless communication and technology, pediatric experts, far from the epicenter of a mass casualty event, may use cellular and wireless capabilities for telemedicine, use resource localization or just-intime training [19, 33•, 34•, 43, 44].

The ability to integrate electronic health records and patient tracking into disaster response may exponentially improve post-disaster follow-up. As highlighted by Barthel et al., reunification after Hurricane Katrina was a disaster in itself [12]. Approximately $75 \%$ of children were still missing 2 weeks after the storm flooded New Orleans. The integration of facial recognition technology, global positioning softwarecontaining wristbands, and cellular devices may assist with communication of important components of a patient's medical record, family, and minimize the psychological trauma associated with surviving a mass casualty disaster.

Finally, long-term follow-up should be part of every emergency preparedness plan. Mental health is an often overlooked in planning but post-traumatic stress may evolve into a chronic health problem if not dealt with after traumatic events. Psychological trauma may be the result from events witnessed during crisis, separation from family and community, or the uncertainty of knowing if things will return to normal. Adjustment reactions can range from depression, anxiety, developmental regression, and physical or somatic manifestations $[15 \bullet \cdot]$. Displacement is often a part of the post-disaster reality for many children, since children are the last members allowed to return to areas ravaged by disasters. Separation from parents, or sheltering outside the home in places such as school or with extended family, can have lasting effects. During the recovery process, community pediatricians can support the establishment of a community infrastructure and continuity to children otherwise living in a disruptive environment, administer vaccinations and medications to prevent secondary disease outbreaks, spearhead public health efforts to provide access to clean water and adequate nutrition, and monitor for long-term effects of toxin or radiation exposure [15••, 45].

\section{Conclusion}

Children are a substantial part of most communities and they have different responses and vulnerabilities than adults in disaster and mass casualty situations. Therefore, leaders crafting all-hazard responses need to incorporate pediatric-specific approaches for education, mass casualty planning and recovery in disaster plans. A community-participatory approach integrating families, physicians, hospital, and community organizations is required if we are to have a successful response and recovery from mass casualty and other disaster events.

\section{Compliance with Ethical Standards}

Conflict of Interest Drs. Zagory, Jensen, Burke, and Upperman declare that they have no conflict of interest.

Human and Animal Rights and Informed Consent This article does not contain any studies with human or animal subjects performed by any of the authors.

\section{References}

Papers of particular interest, published recently, have been highlighted as:

- Of importance

•- Of major importance

1. Burke RV, Iverson E, Goodhue CJ, Neches R, Upperman JS. Disaster and mass casualty events in the pediatric population. Semin Pediatr Surg. 2010;19(4):265-70.

2. Charney R, Rebmann T, Flood RG. Working after a tornado: a survey of hospital personnel in Joplin, Missouri. Biosecur Bioterror: Biodefense Strateg Pract Sci. 2014;12(4):190-200. 
3. Cryer HG, Hiatt JR, Eckstein M, et al. Improved trauma system multicasualty incident response: comparison of two train crash disasters. J Trauma. 2010;68(4):783-9.

4. Espiritu M, Patil U, Cruz H, et al. Evacuation of a neonatal intensive care unit in a disaster: lessons from Hurricane Sandy. Pediatrics. 2014;134(6):e1662-9.

5. Gates JD, Arabian S, Biddinger P, et al. The initial response to the Boston marathon bombing: lessons learned to prepare for the next disaster. Ann Surg. 2014;260(6):960-6.

6. Gausche-Hill M. Pediatric disaster preparedness: are we really prepared? J Trauma. 2009;67(2 Suppl):S73-6.

7. King MA, Dorfman MV, Einav S, et al. Evacuation of intensive care units during disaster: learning from the hurricane sandy experience. Disaster Med Public Health Prep. 2016;10(1):20-7.

8. Stamell EF, Foltin GL, Nadler EP. Lessons learned for pediatric disaster preparedness from September 11, 2001: New York City trauma centers. J Trauma. 2009;67(2 Suppl):S84-7.

9. GBD 2013 Mortality and Causes of Death Collaborators. Global, regional, and national age-sex specific all-cause and cause-specific mortality for 240 causes of death, 1990-2013: a systematic analysis for the Global Burden of Disease Study 2013. Lancet. 2015;385(9963): 117-71.

10. Agran PF, Anderson C, Winn D, et al. Rates of pediatric injuries by 3 -month intervals for children 0 to 3 years of age. Pediatrics. 2003;111(6 Pt 1):e683-92.

11. Agran PF, Winn D, Anderson C, Trent R, Walton-Haynes L. Rates of pediatric and adolescent injuries by year of age. Pediatrics. 2001;108(3):E45.

12. Barthel ER, Pierce JR, Goodhue CJ, et al. Can a pediatric trauma center improve the response to a mass casualty incident? J Trauma Acute Care Surg. 2012;73(4):885-9.

13. Barthel ER, Pierce JR, Goodhue CJ, et al. Availability of a pediatric trauma center in a disaster surge decreases triage time of the pediatric surge population: a population kinetics model. Theor Biol Med Model. 2011;8:38

14. Mortelmans LJ, Maebe S, Dieltiens G, et al. Are tertiary care paediatricians prepared for disaster situations? Prehosp Disaster Med. 2016;31(2):126-31.

15.•- Disaster Preparedness Advisory Council; Committee on Pediatric Emergency Medicine. Ensuring the Health of Children in Disasters. Pediatrics. 2015;136(5):e1407-1417. The Disaster Preparedness Advisory Council of the Committee on Pediatric Emergency Medicine within the American Academy of Pediatrics published this policy statement. Within this paper, they highlight the unique needs of children, the role of the community pediatrician in caring for children and families during a disaster event, and the factors associated with long-term care and recovery efforts

16. Kissoon N, Dreyer J, Walia M. Pediatric trauma: differences in pathophysiology, injury patterns and treatment compared with adult trauma. CMAJ: Can Med Assoc J = Journal de l'Association Medicale Canadienne. 1990;142(1):27-34.

17. Mace SE, Bern AI. Needs assessment: are Disaster Medical Assistance Teams up for the challenge of a pediatric disaster? Am J Emerg Med. 2007;25(7):762-9.

18. Burke RV, Kim TY, Bachman SL, Iverson EI, Berg BM. Using mixed methods to assess pediatric disaster preparedness in the hospital setting. Prehosp Disaster Med. 2014;29(6):569-75.

19. Burke RV, Ryutov T, Neches R, Upperman JS. Health informatics for pediatric disaster preparedness planning. Appl Clin Inform. 2010;1(3):256-64.

20. Ballow S, Behar S, Claudius I, et al. Hospital-based disaster preparedness for pediatric patients: how to design a realistic set of drill victims. Am J Disaster Med. 2008;3(3):171-80.
21. Behar S, Upperman JS, Ramirez M, Dorey F, Nager A. Training medical staff for pediatric disaster victims: a comparison of different teaching methods. Am J Disaster Med. 2008;3(4):189-99.

22. Capella J, Smith S, Philp A, et al. Teamwork training improves the clinical care of trauma patients. J Surg Educ. 2010;67(6):439-43.

23. Cicero MX, Overly F, Brown L, et al. Comparing the accuracy of three pediatric disaster triage strategies: a simulation-based investigation. Disaster Med Public Health Prep. 2016;10(2):253-60.

24. Goodhue CJ, Burke RV, Chambers S, Ferrer RR, Upperman JS. Disaster Olympix: a unique nursing emergency preparedness exercise. J Trauma Nurs: Off J Soc Trauma Nurs. 2010;17(1):5-10.

25. Hamann CJ, Mello E, Wu H, et al. Disaster preparedness in rural families of children with special health care needs. Disaster Med Public Health Prep. 2016;10(2):225-32.

26. McPherson M, Arango P, Fox H, et al. A new definition of children with special health care needs. Pediatrics. 1998;102(1 Pt 1):137-40.

27. Eisenman DP, Zhou Q, Ong M, et al. Variations in disaster preparedness by mental health, perceived general health, and disability status. Disaster Med Public Health Prep. 2009;3(1):33-41.

28. McClure LA, Boninger ML, Oyster ML, et al. Emergency evacuation readiness of full-time wheelchair users with spinal cord injury. Arch Phys Med Rehabil. 2011;92(3):491-8.

29. Goodhue CJ, Demeter NE, Burke RV, et al. Mixed-methods pilot study: disaster preparedness of families with children followed in an intestinal rehabilitation clinic. Nutr Clin Pract. 2016;31(2):257-65.

30. Baker LR, Baker MD. Disaster preparedness among families of children with special health care needs. Disaster Med Public Health Prep. 2010;4(3):240-5.

31. Baker LR, Cormier LA. Disaster preparedness and families of children with special needs: a geographic comparison. J Community Health. 2013;38(1):106-12.

32. Burke RV, Goodhue CJ, Chokshi NK, Upperman JS. Factors associated with willingness to respond to a disaster: a study of healthcare workers in a tertiary setting. Prehosp Disaster Med. 2011;26(4):244-50.

33. Devereaux AV, Tosh PK, Hick JL, 4 Suppl, et al. Engagement and education: care of the critically ill and injured during pandemics and disasters: CHEST consensus statement. Chest. 2014;146:e118S33S. This is a consensus statement put forth by the Task Force for Mass Critical Care, outlining 23 recommendations.

34. Tegtmeyer K, Conway Jr EE, Upperman JS, Kissoon N. Education in a pediatric emergency mass critical care setting. Pediatr Crit Care Med: J Soc Crit Care Med World Fed Pediatr Intensiv Crit Care Soc. 2011;12(6 Suppl):S135-40. Educational approaches are discussed in this Task Force for Pediatric Emergecny Mass Critical Care recommendation, including advance and just-intime training as it pertains to pediatric emergency mass critical care. They highlight the need to identify educational needs, which should guide strategies and tactics to respond to pediatric mass casualty events.

35. Balasuriya D, Iverson E, Burke RV, Upperman JS. Community engagement and pediatric disaster readiness in a large urban disaster resource hospital network: the case of "The Great California ShakeOut". Disaster Med Public Health Prep. 2012;6(2):182-6.

36. Ochoa C, Chokshi N, Upperman JS, Jurkovich GJ, Ford HR. Prior studies comparing outcomes from trauma care at children's hospitals versus adult hospitals. J Trauma. 2007;63(6 Suppl):S87-91. discussion S92-85.

37. Nathens AB, Jurkovich GJ, Maier RV, et al. Relationship between trauma center volume and outcomes. JAMA : J Am Med Assoc. 2001;285(9):1164-71.

38. Rhodes M, Smith S, Boorse D. Pediatric trauma patients in an 'adult' trauma center. J Trauma. 1993;35(3):384-92. discussion 392-383.

39. Fortune JB, Sanchez J, Graca L, et al. A pediatric trauma center without a pediatric surgeon: a four-year outcome analysis. $\mathrm{J}$ Trauma. 1992;33(1):130-7. discussion 137-139. 
40. Hall JR, Reyes HM, Meller JL, Loeff DS, Dembek R. The outcome for children with blunt trauma is best at a pediatric trauma center. J Pediatr Surg. 1996;31(1):72-6. discussion 76-77.

41. Potoka DA, Schall LC, Ford HR. Improved functional outcome for severely injured children treated at pediatric trauma centers. J Trauma. 2001;51(5):824-32. discussion 832-824.

42. Kelen GD, Sauer L, Clattenburg E, Lewis-Newby M, Fackler J. Pediatric disposition classification (reverse triage) system to create surge capacity. Disaster Med Public Health Prep. 2015;9(3):283-90.
43. Curtis JW, Curtis A, Upperman JS. Using a geographic information system (GIS) to assess pediatric surge potential after an earthquake. Disaster Med Public Health Prep. 2012;6(2): $163-9$.

44. Burke RV, Berg BM, Vee $\mathrm{P}$, et al. Using robotic telecommunications to triage pediatric disaster victims. J Pediatr Surg. 2012;47(1):221-4.

45. Medical countermeasures for children in public health emergencies, disasters, or terrorism. pediatrics. 2016;137(2):1-9. 